Volume 8, No.1.3, 2019

International Journal of Advanced Trends in Computer Science and Engineering

Available Online at http://www.warse.org/IJATCSE/static/pdf/file/ijatcse2681.32019.pdf

https://doi.org/10.30534/ijatcse/2019/2681.32019

\title{
Analyzing the Barrier to Open Government Data (OGD) in Indonesia
}

\author{
Deden Witarsyah Jacob ${ }^{1}$, Mohd Farhan Md Fudzee², Mohamad Aizi Salamat ${ }^{2}$, Nurul Hidayah Ab \\ Rahman $^{2}$ \\ ${ }^{1}$ Information System Department, Telkom University Jln Telekomunikasi no. 1 Bandung, Indonesia, \\ dedenw@telkomuniversity.ac.id \\ ${ }^{2}$ Faculty of Computer Science and Information Technology, Universiti Tun Hussein Onn Malaysia
}

\begin{abstract}
Public services such as Open Government Data (OGD) already become a new trend for the people and it has been recognized that OGD not only accelerates the development of digital technology but also substantially boosts economic growth and contributes to improve of sustainable economies. Whereas nearly all scholars are receiving an hopeful see of OGD, there are the issues where that numerous governments are cautious and indeed hesitant to open their information. This study proposes a theoretical framework of obstacle to OGD that seeks to identify, understand and qualify barriers in the release of OGD in Indonesia and then can be adopted as a basis for empirical investigation. This study applied literature analysis combined with the interview approach. The findings identified 10 barriers to the release of OGD in Indonesia that emerged in the following two main themes: institutional barriers and information quality barriers.
\end{abstract}

Key words : Barriers, Open government, Open government data, Theoretical framework, Indonesia Government as.

\section{INTRODUCTION}

Open government data (OGD) has ended up a worldwide marvel nowadays that quickens innovation improvement as well as significantly boosts financial development and contributes to the creation of economical economies [3], [8],[5],[9]. Moreover, OGDs have a strong ability to change existing business models in government through increased participation and transparency of individuals [14], [2], [5] and effectively reducing corruption [1], [9].

With benefits such as greater trust, support, and better acceptance in political decisions in governments. In the context of Indonesia's government, the realization of clean, effective, democratic, and reliable governance poured President Joko Widodo into the Nawa Cita program as the basis of the Indonesia's government mission [26]. One of the steps taken is to continue efforts to build a more open, participative, and innovative government through the Open Government Indonesia (OGI) commitment a concrete form of the Indonesian government's seriousness in conducting public sector reform in Indonesia as a whole.

OGI is expected to be born ideas, initiatives, and practices of government openness to all levels of society in collaborating and accelerating the achievement of national targets and priorities. It is significantly would strengthen the quality of public policy innovations to fit the public needs and implementation of the government.

The systematic organization of the paper is Section 1 explains about introduction; Section 2 covers the theoretical basic and background; Section 3 justifies the review method and process, Section 4 describes the finding; Section 5 discusses the result and their implications; Section 6 concludes this study.

\section{RELATED WORKS}

\subsection{Global OGD Movement}

OGD is often concluded as a more comprehensive e-government development [9]. Refers to the OGD Working Group[16], the OGD is defined as government-generated data and data that can be freely used, and then reusable and distributed by anyone. Meanwhile, many scholars highlight that OGDs not only make the data publicly available freely but also have to establish effective technology platforms that allow better access and public exploitation [10],[18],[12].

It has been widely acknowledged that the launch of the OGD commenced when the former United States President, Mr. Barack Obama inaugurated its utilization in year 2009 [6], [12],[17],[1]. Open data of the United States government, is one of Mr. Obama's first program to starts an advanced level of open data in the government [15].

\subsection{OGD Development in Indonesia}

The Presidential Decree has been supplemented with guidelines that govern all government actors for digital-government development published by the Ministry of Communications and Information in 2003 [27]. Six guidelines were issued consisting of quality standards and service coverage, as well as e-government application development, institutionalization, authority, information and 
business engagement in digital-government development, development of good governance and change management, digital-government project assignment and financing, digital-government competency standards, and the latest blueprint digital-government application for the central government and local governments [25].

Examples of public policy innovations supported by the Open Government Indonesia (OGI) including Layanan Aspirasi dan Pengaduan Online Rakyat (LAPOR), One Data Portal, and One Map initiative. The three innovations are public policy instruments that attempt to target the three very closely related regions with increased government openness.

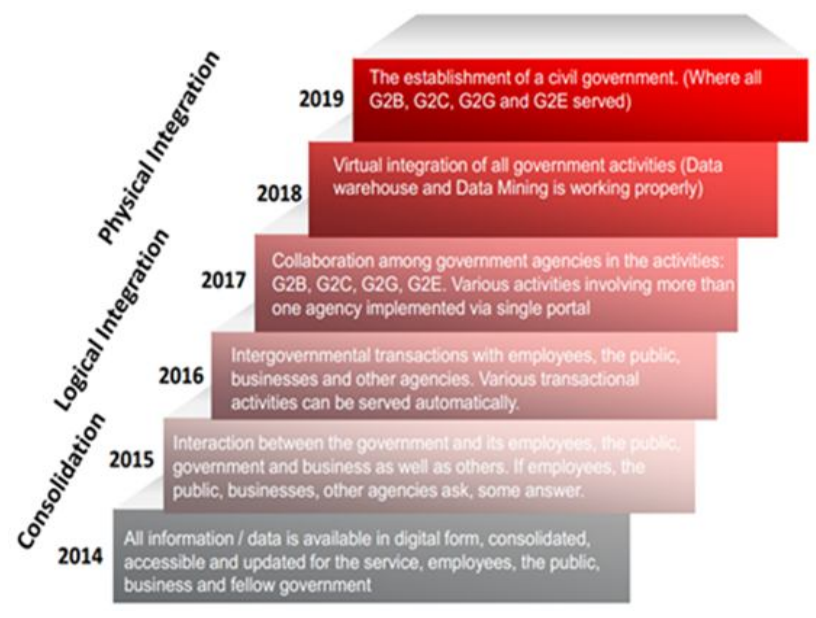

Figure 1: Roadmap of digital-government Indonesia 2014-2019 [25]

There are the desire channel and open grievances for (LAPOR), at that point the nearness of sound information as a wellspring of open strategy improvement through open information, and the accessibility of spatial information (space) that is firmly identified with advancement arranging through one guide [22-24,26]. Figure 2 shows the full impact of OGI's activities from overall impacts, ongoing commitments to initiatives that have been implemented such as Aceh city, Jakarta Province, Bandung city, Semarang city and Bojonegoro District.

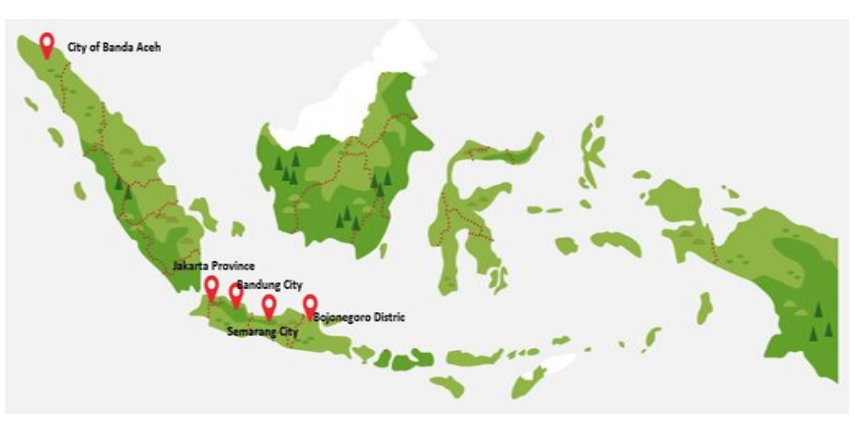

Figure 2: Innovations open government data in Indoensia

While most researchers are optimistic about the adoption of DOGs, however, there are barriers in government's data openness. As observed by Zuiderwijk and Janssen [20], the main obstacle was access to inappropriate and effective data sets from users' perspective.

\section{REVIEW METHODS AND PROCESSES}

\subsection{Research Objectives and Questions}

To understand the obstacles in the implementation of OGD in Indonesia formulated a research question that is: what factors that hamper the implementation of OGD in Indonesia? Furthermore, literature studies were used to conduct a research approach [7]. The literature review aims to develop a conceptual framework through systematic data collection through the selection, analysis and synthesis of the literature.

\subsection{Literature retrieval and Interview selection}

The method was undertaken in two stages. First stage includes reviewing the theories relating to OGD development in both English and Indonesia literatures and second stages is interview. It should be noted that the study literature was conducted in Indonesian and English. Moreover, this article has been published between 2010 and 2017, then around 2015 and 2016 open data government a very interesting attention for researchers to learn it.

Overall, 100 articles were obtained from science direct and emerald, all the articles taken were carefully studied. some additional information for the development and problems of open data government in Indonesia can be through interview process at local government office. For more details see Figure 1 of the flow diagram.

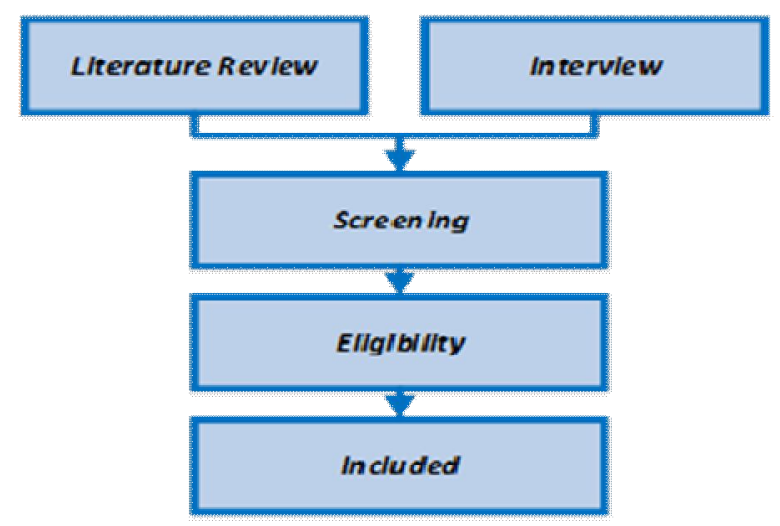

Figure 3: Processes of literature and interview selection using a flow diagram

\subsection{Literature and interview analysis}

This study used explorative and thematic analyzes [13] and focused only on institutional and information quality barriers. The data in this study were taken from the article through literature search. In addition, the barrier adopts the adoption of OGDs provided by Janssen et al [8] have been used as early thematic examples in the orientation and compilation of 
literature analysis. On the other hand, this framework is only focus on two categories and consists of ten barriers namely: 1. Institutional barriers include: there is no uniform policy for the OGD; provision of non value-added data; no resources to publish data; there is no process to handle user input; low quality for user input.

2. Information quality barriers include: lack of accuracy of information; incomplete information; obsolete and invalid data.

\section{FINDINGS}

The literature review shows that OGD development and difussion in Indonesia has not been very successful and only in the early stages of exploitation. The literature analysis shows ten barriers, which fall within two theoretical themes: institutional barriers and information quality barriers. Findings of this study are, however, not covered all the categories of OGD obstacles in Janssen et al. [8].

\subsection{Institutional Barriers}

Several institutional barriers have identified from literature analysis and interviews significantly impeding the development and diffusion of OGDs in Indonesia, as follows:

(1) The conflict between the traditional bureaucracy and the OGD;

(2) The culture of risk aversion and resistance of the OGD;

(3) Lack of a proper understanding of the value of the OGD;

(4) Data viewed as personal resources, benefits and resources;

(5) Lack of OGD collaboration between departments/ agencies; and

(6) Lack of specific and integrated OGD policies.

It has been identified that OGDs have the potential to revolutionize and substantially change the original bureaucratic structure of the Government of Indonesia, as echoed in Zhang [29], although Tan[28] pointed out that the government is always closed and accustomed to keeping secrets from the general public.

\subsection{Information Quality Barriers}

Information quality have been identified as a new theme in the literature analysis and the following four specific barriers have emerged:

(1) Data fragmentation, scatteration and duplication;

(2) Absence of unified and clear standards for OGD structure and metadata;

(3) Overly simplified, obsolete or invalid data; and

(4) A lack of maintenance or a timely update.Developing a harmonized standards and formats for data management would be a promising approach to solve poor quality of data in OGDs.

\section{DISCUSSIONS}

The deep analysis approach was empowered in this research to review and interview articles for formulating and developing inductive theories in generating a structured theoretical narrative [19]. On this stages, the expected conceptual model can be formulated to informed a theoretical basis for future research and to provide a pragmatic and effective resolution strategy. Therefore, the literature is analysed and conceptualized through an understanding of the relationship between individual OGD obstacles identified from the author's perspective. Thus, the conceptual framework is built and presented in Figure 4.

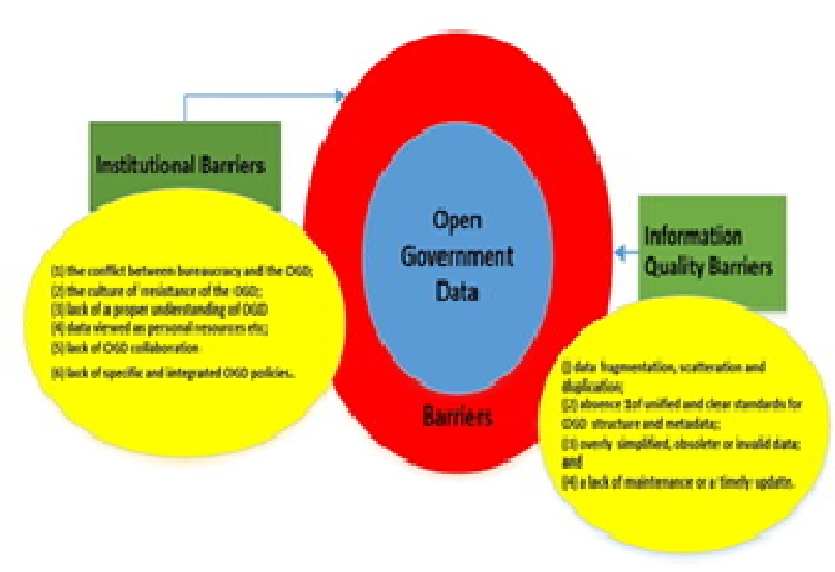

Figure 4: Proposed frameworks of barriers

\section{CONCLUSION}

A systematic literature review was founded and present in this study that aims to identify, understand and qualify barriers that hinder opening government data in Indonesia. Results of the literature analysis showed that despite clear high-level political decisions and determination, the OGD development in Indonesia has proven to be highly problematic. Ten OGD barriers were identified that can be broadly categorized into two main themes: (1) institutional barriers and (2) information quality barriers. Furthermore, the literature analysis pointed to mitigating strategies to resolve the barriers identified.

\section{REFERENCES}

1. S Attard, J., Orlandi, F., Scerri, S. and Auer, S. (2015), “A systematic review of open government data initiatives", Government Information Quarterly, Vol. 32 No. 4, pp. 399-418. https://doi.org/10.1016/j.giq.2015.07.006

2. Bertot, J.C., Jaeger, P.T. and Grimes, J.M. (2010), "Using ICTs to create a culture of transparency: e-government and social media as openness and anti-corruption tools for societies", Government Information Quarterly, Vol. 27 No. 3, pp. 264-271. https://doi.org/10.1016/j.giq.2010.03.001

3. Borzacchiello, T.M. and Craglia, M. (2012), "The impact on innovation of open access to spatial environmental information: a research strategy", 
International Journal of Technology Management, Vol. 60 Nos 1/2, pp. 114-129.

https://doi.org/10.1504/IJTM.2012.049109

4. Boulton, G.S., Rawlins, M.D., Vallance, P. and Walport, M.J. (2011), "Science as a public enterprise: the case for open data", The Lancet, Vol. 377 No. 9778, pp. 1633-1635.

https://doi.org/10.1016/S0140-6736(11)60647-8

5. Conradie, P. and Choenni, S. (2014), "On the barriers for local government releasing open data", Government Information Quarterly, Vol. 31 No. S1, pp. S10-S17. https://doi.org/10.1016/j.giq.2014.01.003

6. Ganapati, S. and Reddick, C.G. (2012), “Open e-government in US state governments: survey evidence from chief information officers", Government Information Quarterly, Vol. 29 No. 2, pp. 115-122.

https://doi.org/10.1016/j.giq.2011.09.006

7. Grant, M. and Booth, A. (2009), "A typology of reviews: an analysis of 14 review types and associated methodologies", Health Information and Libraries Journal, Vol. 26 No. 2, pp. 91-108.

https://doi.org/10.1111/j.1471-1842.2009.00848.x

8. Janssen, M., Charalabidis, Y. and Zuiderwijk, A. (2012), "Benefits, adoption barriers and myths of open data and open government", Information Systems Management, Vol. 29 No. 4, pp. 258-268. https://doi.org/10.1080/10580530.2012.716740

9. Jetzek, T., Avital, M. and Bjorn-Andersen, N. (2014), "Data- driven innovation through open government data", Journal of Theoretical and Applied Electronic Commerce Research, Vol. 9 No. 2, pp. 100-120. https://doi.org/10.4067/S0718-18762014000200008

10. Kalampokis, E., Tambouris, E. and Tarabanis, K. (2011), "A classification scheme for open government data: towards linking decentralised data", International Journal of Web Engineering and Technology, Vol. 6 No. 3, pp. 266-285.

https://doi.org/10.1504/IJWET.2011.040725

11. Kassen, M. (2013), "A promising phenomenon of open data: a case study of the Chicago open data project", Government Information Quarterly, Vol. 30 No. 4, pp. 508-513. https://doi.org/10.1016/j.giq.2013.05.012

12. King, N. and Horrocks, C. (2010), Interviews in Qualitative Research, Sage, London.

13. Mc Dermott (2010), "Building open government", Government Information Quarterly, Vol. 27 No. 4, pp. 401-413. https://doi.org/10.1016/j.giq.2010.07.002

14. Obama, B. (2009a), "Transparency and open government: memorandum for the heads of executive departments and agencies".

15. Open Knowledge Foundation (2016), "What is open government data",

16. Veljkovic, N., Bogdanovicdinic, S. and Stoimenov, L. (2014), "Benchmarking open government: an open data perspective", Government Information Quarterly, Vol. 31 No. 2, pp. 278-290. https://doi.org/10.1016/j.giq.2013.10.011

17. Weerakkody, V., Irani, Z., Kapoor, K., Sivarajah, U. and Dwivedi, Y.K. (2017), "Open data and its usability: an empirical view from the citizen's perspective", Information Systems Frontiers, Vol. 19 No. 2, pp. 285-300. https://doi.org/10.1007/s10796-016-9679-1

18. Zhou, L.H. and Nunes, M.B. (2016), "Barriers to knowledge sharing in Chinese healthcare referral services: an emergent theoretical model", Global Health Action, Vol. 9 No. 1.

https://doi.org/10.3402/gha.v9.29964

19. Zuiderwijk, A. and Janssen, M. (2014a), "Barriers and development directions for the publication and usage of open data: a socio-technical view", in Gascó-Hernández, M. (Ed.), Open Government, Springer, New York, NY, pp. 115-135. https://doi.org/10.1007/978-1-4614-9563-5_8

20. Zuiderwijk, A. and Janssen, M. (2014b), "The negative effects of open government data-investigating the dark side of open data", in Zhang, J. and Gil-Garcia, J.R. (Eds), Proceedings of the 15th Annual International Conference on Digital Government Research in Aguascalientes, Mexico, ACM, New York, NY, pp. 147-152. https://doi.org/10.1145/2612733.2612761

21. D. W. Jacob, M. F. Fudzee, and M. A. Salamat, "A Conceptual Study on Generic End Users Adoption of electronic-government Services," Int. J. Adv. Sci. Eng. Inf. Technol., vol. 7, no. 3, pp. 1000-1006, 2017. https://doi.org/10.18517/ijaseit.7.3.1654

22. D. W. Jacob, M. F. Md Fudzee, M. A. Salamat, S. Kasim, H. Mahdin, and A. A. Ramli, "Modelling End-User of electronic-Government Service: The Role of Information quality, System Quality and Trust," IOP Conf. Ser. Mater. Sci. Eng., vol. 226, p. 12096, Aug. 2017. https://doi.org/10.1088/1757-899X/226/1/012096

23. D. W. Jacob, "The Critical Factors Affecting e-government Adoption in Indonesia: A Conceptual Framework," Int. J. Adv. Sci. Eng. Inf. Technol., vol. 7, no. 1, pp. 160-167, 2017 https://doi.org/10.18517/ijaseit.7.1.1614

24. Cetak Biru Sistem Aplikasi digital-government. Bappenas. 2003.

25. Rencana Pembangunan Jangka Menengah Nasional 2015-2019

26. Inpres No.3 Tahun 2003. Pemerintah Republik Indonesia.

27. Tan, J. (2016), “Obstacle factors of open government data: analysis based on the TOE theoretical framework", Journal of Intelligence, Vol. 35 No. 8, pp. 175-178.

28. Zhang, L. (2016a), "Research on mechanism of open government data in China in the big data environment", E-Business Journal, Vol. 22 No. 10, pp. 8-9. 